\title{
Caminhos para a Construção de um Futuro com Esperança
}

\author{
Maria Helena Novaes ${ }^{1}$ \\ $P U C-R J$
}

\begin{abstract}
Resumo
O desafio atual da educação é o de incentivar caminhos criativos para se construir um mundo futuro com esperança, face às repetidas mudanças de vida cotidiana da organização social, das formas de comunicação, das instituições e da cultura através de uma visão transdisciplinar lúcida, crítica e realista, poderá se perceber melhor o que é mais essencial para a sobrevivência da humanidade, o que pressupõe articular ciências, artes, tecnologia e crença. Propõe-se a "razão aberta" como modelo no sentido de assimilar os elos da cadeia: ordem e desordem, interação e organização no paradigma da complexidade, assim como a do jogo combinatório, a do sistema de unidade complexa, considerando a metamorfose epistemológica, dentro de uma ética que garante a qualidade de vida, a conquista da autonomia na base de interdependência das gerações com um novo olhar da razão, verdade, memória e história.
\end{abstract}

Palavras-chave: criatividade, futuro, complexidade.

\section{Ways to Construct a Future World with Hope}

\section{Summary}

Today's challenge of education is to find criative ways to construct a future world with hope face the rapid changes in daily life, as well as in the social organization, forms of comunication, institutions and culture. Though a transdisciplinary vision clear critical and realistic one can see better what is more essencial to humen survival, which presumes an articulation with science art, techonology and faith. We propose the "open reason" as a model in the sense of assimilate the rings of the chain: order and disorder, interaction and organization a complexity paradigm as well as the one of a combinatory game, a system of complex unity, considerary the espistemological metamorphosis searching na other that can provid the quality of live, the autonomy by the interdependence of genrations with a new look of reason, truth memory and history.

Key words: creativity, future, complexity.

$$
\begin{array}{r}
\text { "O passado é o lastro } \\
\text { O presente, a sinalização } \\
\text { Mas, o futuro é a conquista" }
\end{array}
$$

Cada vez fica mais claro que o futuro não pode ser concebido como mero prolongamento do passado ou, apenas, como oportunidade para resolver dificuldades do presente, pois tenderia a fracassar como proposta de renovação e de abertura para o destino da humanidade.

Sem dúvida, a incerteza e a complexidade permeiam essa construção, pontuada por crises históricas, sociais, morais ou econômicas, questionamentos éticos, morais e visões de mundo.

Uma postura otimista ou ingênua no sentido de prever um futuro promissor não satisfaz, assim como aquela catastrófica e dramática antecipando desastres e cataclismas. O importante é uma visão lúcida, crítica e realista, capaz de perceber o que é essencial para a sobrevivência da humanidade, respeitando valores, aproveitando erros históricos, procurando novas e significativas alternativas de convivência humana, a fim de se chegar a um futuro reconhecível e viável. Aliás, Ítalo Calvino destacava dentre suas propostas para o Terceiro Milênio, a "visibilidade", cotejando com as demais leveza, rapidez, exatidão, multiplicidade e consistência, no sentido de procurar ver

\footnotetext{
${ }^{1}$ Endereço: Rua General Rabelo. 65 - C. 2. Gávea CEP: 22451-010 - Rio de Janeiro - RJ - Brasil.
} 
sempre com alcance antecipatório. Eric Hobsbawn no seu livro "A Era dos Extremos", no qual defende a tese do "breve século XX (1914-1991)", afirma que enquanto houver raça humana, haverá sempre história e destaca que o fundamental é superar o mal estar do resto, a precariedade dos sistemas, para que o mundo não acabe numa simples lamúria. Há riscos a enfrentar pois experiências demonstram que a corrosão da legitimidade dos saberes, o desordenamento institucional, a brutalização política, a banalização da vida humana, a irresponsabilidade social, a desorientação do poderio econômico, o declínio das religiões e dos valores morais trazem conseqüências, muitas delas, irreversíveis.

O presente já sinaliza, por exemplo, que os avanços científicos, a alta tecnologia, a modernização e globalização da sociedade desvinculada de uma sólida revisão dos valores humanos não garantem a construção de uma sociedade consciente, responsável e esperançosa.

Sem uma consciência paralela aos apot1es científicos e uma compreensão dos fenômenos, tanto físicos, sociais, culturais, ecológicos à luz de uma visão transdisciplinar, que analisa seus desdobramentos nas questões éticas é difícil avançar para um real progresso das ciências a favor do homem e da evolução da raça humana.

Edgar Morin no seu livro Ciência com Consciência, discute a idéia do progresso do conhecimento, a responsabilidade do pesquisador perante a sociedade e o homem, e propõe uma razão aberta que assimile os elos da cadeia: ordem, desordem e complexidade. Desenvolve o tetragrama seguinte:

Entende o universo a partir de uma dialógica entre esses termos, cada um deles chamando o outro, precisando do outro para se constituir cada um inseparável e complementar do outro, apesar de ser também antagônico do outro.

As idéias de desordem e complexidade não podem ser eliminadas do universo, são variáveis para concebê-lo na sua natureza e evolução. Embora pareça haver uma contradição lógica na associação da idéia de ordem e desordem, os fatos comprovam que existe uma real associação entre elas.

É na imaginação produtiva do grande matemático Thom que Monod, Prigogine, Srengers, Atlan fazem a apologia da desordem, configurada como um princípio de ordem, a partir do barulho (von Foerster) do acaso organizador (Atlan) da ordem por flutuação (Prigogine). Na ordem do cosmos, a agitação e as turbulências podem não só criar a desordem, mas também a organização. Assim, para conceber o mundo dos fenômenos, precisamos partir desse jogo combinatório.

As galáxias esbarrando nos violentos estalos da gestação das estrelas liberam explosões de radiação de energia equivalentes a milhares de holocaustos nucleares.

Segundo os astrônomos F. Schweizer e B. Miller, desse encontro se formam apocalípticos furacões de gás incandescente, que se deslocam a velocidade vertiginosas, porém não há autodestruição nesse caos, dono e senhor absoluto, como demonstram as imagens do Hubble, pois nascem sempre novas e refulgentes estrelas. 
Por outro lado, as galáxias, assim como as pessoas, não gostam de ficar isoladas, agrupam-se em pares que, a seu turno, formam grandes famílias.

O ideal seria, como imagina o escritor poeta Paulo Novaes, "podermos viajar pelo universo, visitar galáxias, chutar asteróides pelas esquinas do céu, nos hospedarmos em planetas de outros sistemas parecidos com o nosso, brincarmos de soltar pipas nos gramados estrelados em que as linhas são caudas de cometas pirotécnicas".

Entretanto, a problemática do sistema não se resolve somente na relação todo-partes; o próprio paradigma holista esqueceu dois termos capitais - interação e organização, pois tanto o todo como as partes devem ser mediatos pelas interações, sendo o conjunto dessas interações que constitui a própria organização do sistema, dando coerência construtiva, regras, regulação e estrutura às interações. O sistema seria a unidade complexa; a interação, o conjunto das relações e ações; a organização, o caráter constituído dessas interações, conceito esse de caráter paradigmático superior.

A primeira revolução do pensamento manifesta-se assim na ciência da organização e na nova noção de autonomia, considerando que um sistema aberto é aquele que pode alimentar sua autonomia mediante a dependência em relação ao meio externo, envolvendo a auto-organização, ou seja, aquela que se auto-repara e se reorganiza.

A própria revolução em marcha no mundo das ciências prevê uma metamorfose epistemológica na qual se admitirão sistemas irracionais, imprevisíveis e, até certo ponto, caóticos. O fato é que as delimitações dos campos científicos estão desaparecendo; a evolução da informática, a digitalização de imagens, as novas tecnologias de produção, captação, transmissão, reprodução e armazenamento de informações, a realidade virtual levarão o homem a evoluir nas interfaces dos saberes, operando mais nas dimensões da profundidade e intensidade, assim como tanto na unidade como na diversidade.

Nessa virada de século questionar o "ser livre" e o "ser autônomo" é muito importante porque daí advirá a capacidade de se aceitar o novo e o risco da tomada de posições.

Sem dúvida, presenciamos os desvios e equívocos da ética num mundo unidimensionado como um grande mercado e uma sociedade de negociação globalizada.

A reflexão da ética diz respeito a quais demandas morais os seres humanos podem legitimamente se preocupar, oferecendo respostas para uma avaliação prática no cotidiano e na interação social. Federico Mayor, diretor da UNESCO, por ocasião da abertura da $3^{\text {a }}$ Reunião da Agenda Millenium, em julho de 1997 no Rio, afirmou: "Na ética do futuro frágil e perecível é preciso integrar a herança universal, garantir a qualidade de vida a fim de que todos compreendam o mundo complexo e rico da ciência e da cultura que será construído a partir dos valores que cultivamos desde agora".

Sabemos que o sentimento de impotência e de irresponsabilidade do ser humano leva ao descompromisso, pois de antemão, percebe que nada dependerá dele para a melhoria da humanidade, o que o marginaliza dos problemas sociais e acarreta certa "anorexia moral", não sabendo aproveitar erros, nem novas formas de interação.

Ao fazer frente a tais elementos corrosivos conservando padrões de sensibilidade compatíveis com seus desejos, metas e propostas, utiliza sua emoção e sentimento nas suas escolhas, pensa numa ética compartilhada com os outros na busca de mundos melhores. São caminhos viáveis, bem como lidar com a ressonância dos acontecimentos, compreendendo que o bem e o mal estão 
configurados pelos contextos culturais e históricos. Tais recursos são importantes para enfrentar o desconhecido de um futuro e as grandes mudanças que advirão.

O teólogo Tillich já afirmava: "Para o homem ameaçado constantemente pela morte, onticamente pelo pecado e espiritualmente pelo absurdo, a realidade incondicionada se revela como fundamento e abismo, realidade infinita e absoluta. Justiça, paz, fraternidade e solidariedade não podem ser privatizadas no sentido de serem um bem individual, mas devem estar ligados a experiências de fé".

Urge direcionar ações no futuro para o vetor da troca intergeracional com qualidade de vida e para o resgate social capacitando as pessoas para serem protagonistas das próprias vidas, através da cooperação, da auto-estima, constituindo-se em agentes de mudança social. Aspectos relevantes a considerar seriam as possibilidades de realização pessoal, o respeito às diferenças, a conquista da autonomia na base da interdependência, a criação de vínculos sociais, a distribuição do poder com a eleição consciente de quem afinal determina e da constante participação nesse contexto.

O jogo das aparências está também sempre presente, como afirma M. Maffesoli, sendo lugar visível, muito ligado ao atual hedonismo do cotidiano irreprimível e poderoso que sustenta a vida em sociedade e que pontua os desvios, as prioridades e a valorização de tais ou quais comportamentos e atitudes.

É importante analisar as representações simbólicas, os mitos e concepções abstratas do "social" nas suas diversas metáforas como "corpo", "jogo", "tecido", "trama", todos questionando o "vínculo" e a "invenção" do social propriamente dito.

O fato é que a reinvenção do social só pode ser feita num campo de lutas, no qual igualdade não pressupõe anulação das diferenças, uma vez que estas constituem uma das faces do próprio fenômeno da identidade.

Considerar, por outro lado, as modificações dos direitos do homem, como propõe N. Bobbio no seu livro A era dos direitos, num padrão civilizatório, ético e político é fundamental.

Contradições e incertezas estarão sempre presentes, cabe portanto aos homens encontrarem caminhos e alternativas que viabilizem a expansão do conhecimento e do saber com vistas à promoção e o bem-estar social de todos, além da construção de um mundo mais justo, humano e criativo.

Sem dúvida, o novo e o desconhecido assustam porque pressupõem o livre e o criativo, inquietam porque não nos obrigam a acertar, mas sim a experimentar, inaugurando novas formas de se relacionar com esse mundo finissecular.

O fato é que convivemos com novos tecidos sociais e científicos constituídos de múltiplas tramas e de fenômenos complexos de organização social; contradições dessa neo-realidade cultural provocam modificações no modo de transmitir, decodificar, distribuir, reproduzir e memorizar informações que constituem o líquido amniótico da humanidade. Nesse mundo em transformação só uma consciência crítica levará a uma leitura articulada com a singularidade e a historicidade na busca da totalidade social.

Em síntese, o grande desafio do homem futuro será como sair dos impasses, a fim de resingularizar uma subjetividade criativa e polifônica estabelecida numa cartografia, ao mesmo tempo individual e coletiva, com um novo olhar da razão, verdade, memória e história; ao conviver com a ambigüidade, transcendendo dualidades, enfrentará mutações processuais, conquistará novas relações entre os saberes, ao mesmo tempo podendo resgatar a emoção e a paixão numa visão de 
mundo futuro.

Por outro lado, ao transitar pelo sutil e o evidente, o singular e o múltiplo, o exato e o ambíguo, a aparência e a realidade nas suas relações com o mundo, poderá substituir o desencanto do monótono e do trivial pelo encantamento do espanto - quem sabe então, se o novo calendário de imprevistos o deixará mais criativo e autêntico, apesar de mais perplexo e vulnerável, encontrando caminhos que representem saídas para a construção de um futuro com esperança, configurado num eterno renovar do cotidiano e da convivência humana, através de seus desejos, sentimentos e sonhos, bem como o vai e vem das identidades, lembrando que quem planeja o importante sabe transformá-lo em pequenas coisas.

\section{Referências}

Bobbio, N. (1992). A era dos direitos. Rio. Campus. Calvino, I. (1990). Seis propostas para o terceiro milênio. São Paulo, Cia. das Letras.

Castel, B. (1995). Les métamorphoses de la question sociale. Paris, Fayard.

Freire, J. (1997). Ética e educação. Rio: Seminário Pue.

Hobsbawn, E. (1995). A era dos extremos. São Paulo, Cia. das Letras.

M. Maffesoli, M. (1996). No fundo das aparências. Petrópolis, Vozes.

Morin, E. (1996). Ciência com consciência. Rio: Bertrand.

Novaes, M. H. (1996). A transição sociocultural contemporânea: seus desdobramentos na organização do conhecimento e no pensamento criativo. Psicologia Clínica, 7. PUC-Rio, 7-24.

Schnitman, D. E. et al. (1994). Nuevos paradigmas cultura y subjetividad. Buenos Aires, Paidós.

Prigogine, F. e Stengers, T. (1986). A nova aliança. Lisboa: Ed. Gradiva. 